\title{
"INVISIBILITY OF THE MALE" AS A MARKER OF GENDER INEQUALITY IN THE THEORY OF MICHAEL KIMMEL
}

\author{
Ekaterina B. Khitruk \\ Tomsk State University, Tomsk, Russian Federation
}

\begin{abstract}
This article explores the problem of gender inequality in the theory of the famous American sociologist Michael Kimmel. It reveals the fundamental culture settings that promote the reproduction of gender inequality in modern society. The main of the indicated installations are the following: 1. Universalization of the masculine, identification of the masculine with the universal and objective. This installation contributes to the invisibility of male gender in the social space. 2. Biologization of gender differences, the adoption of logic "from the natural to the social." An appeal to natural order legitimizes gender inequality, representing a historically established hierarchy as a biologically determined invariant. 3 . The idea of male in culture is closely related to violence. The status of a "real man" is played out as a trophy in the course of implementing various practices of sexual, domestic, ethnic violence. The article concludes that gender inequality produces binary opposition of male and female in culture. However, a significant rethinking of the concepts of masculinity and femininity has already found place in society. As a result of this rethinking, the imperative of opposing male and female "nature" is consistently mitigated.Thus, masculinity and femininity are seen in Michael Kimmel's theory as social categories, the content of which must be reviewed every time humanity comes to a new level of self-understanding.
\end{abstract}

Key words: Michael Kimmel, gender inequality, binary oppositions, gender of violence, male, masculinity, biological determinism.

УДК 141.7

ББК 60.52

\section{«НЕВИДИМОСТЬ МУЖСКОГО» КАК МАРКЕР ГЕНДЕРНОГО НЕРАВЕНСТВА В ТЕОРИИ МАЙКЛА КИММЕЛА}

\author{
Екатерина Борисовна Хитрук \\ Томский государственный университет, г. Томск, Российская Федерация
}

\begin{abstract}
Аннотация. В данной статье исследуется проблема гендерного неравенства в теории известного американского социолога Майкла Киммела. Раскрываются фундаментальные установки культуры, способствующие воспроизводству гендерного неравенства в современном обществе. Основными из указанных установок признаются следующие: 1) универсализация мужского, отождествление мужского с общечеловеческим и объективным. Данная установка способствует невидимости мужского гендера в социальном пространстве; 2) биологизация половых различий, утверждение логики «от природного к социальному». Апелляция к естественному порядку легитимирует неравенство полов, представляя исторически сложившуюся иерархию как биологически детерминированный инвариант; 3) представление о мужском в культуре тесно связано с насилием. Статус «настоящего мужчины» разыгрывается как трофей в процессе реализации разнообазных практик сексуального, бытового, этнического насилия. В статье делается вывод о том, что гендерное 궁 неравенство продуцирует бинарную оппозицию мужского и женского в культуре. Однако в обществе уже คे имеет место существенный пересмотр представлений о мужественности и женственности. В результате этого пересмотра происходит последовательное смягчение императива противопоставления мужской и женской «природы». Таким образом, мужественность и женственность рассматриваются в теории Майкла Киммела как социальные категории, содержание которых должно пересматриваться каждый раз, когда чело(2) вечество выходит на новый уровень понимания себя.
\end{abstract}


Ключевые слова: Майкл Киммел, гендерное неравенство, бинарные оппозиции, гендер насилия, мужское, маскулинность, биологический детерминизм.

Привилегия невидима для тех, у кого она есть.

Майкл Киммел

«Активность/пассивность, солнце/луна, культура/природа, умозрение/ощущение, логос/патос... Всегда одна и та же метафора: мы ей следуем, она увлекает нас, какой бы фигурой ни облекалась, всюду, где выстраивается дискурс. Одна и та же нить, или двойная прядь, ведет нас, коль скоро мы читаем или говорим, сквозь лабиринт литературы, философии, критики, столетия репрезентации, рефлексии» [3, с. 48], - так Элен Сиксу подчеркивает зависимость любых попыток осмысления реальности от бинарного принципа различения и противопоставления. Является ли предметом нашего интереса бытие, социум или человек, мышление выделяет в этом предмете различные стороны и выстраивает оппозиционные отношения между ними, обозначая данный процесс как понимание или познание.

Половое измерение человека также прошло через этот сложный процесс выделения противоположностей и закрепления оппозиционной (бинарной) иерархии между ними. Многие столетия человеческой истории философская рефлексия закрепляла за мужским и женским различные проявления человеческой природы, рассматривая их как некие незыблемые сущности, естественно продуцирующие механизмы социального неравенства. Таким образом, эссенциальная принадлежность женского к пассивному, телесному, природному, чувственному рассматривалась в качестве причины для «естественного» лишения женщин права на образование, а также политических и экономических прав и свобод. Однако общий принцип базирующей такое рассуждение логики - «от естественного к социальному» или «от различия к неравенству» был подвергнут существенному пересмотру в социальной теории XX века. Одним из крупнейших критиков «естественной» теории половых различий выступает знаменитый американский социолог Майкл Киммел. «Я утверждаю, - пишет Киммел в своем знаменитом исследовании «Гендерное общество», - что гендерное различие - утверждение двух качественно различных сущностей - является результатом гендерного неравенства, а не его причиной. Гендерное неравенство производит различие, и произведенные различия затем используются, чтобы оправдать гендерное неравенство» [2, с. 10].

В отличие от классической полоролевой концепции, теория М. Киммела исходит из убеждения, согласно которому гендер не является естественным выражением на социальном уровне биологически обусловленных половых различий. Социальная репрезентация мужественности и женственности имеет прямое отношение к культурным механизмам воспроизводства властных отношений в обществе, и именно поэтому она теснейшим образом связана с иерархией и подавлением. Социальное, политическое и экономическое неравенство мужчин и женщин в современном обществе наряду с более сложным гендерным неравенством в контексте расовых, классовых, возрастных и сексуальных различий не является продуктом биологии, но, скоpee, должно быть рассмотрено в качестве причины закрепления в культуре концепта «естественной противоположности полов».

Чрезвычайная важность различения и противопоставления мужского и женского в большинстве известных науке культур продуцирует, таким образом, не убеждение в биологической фундированности пола, а скорее осознание необходимости тщательного и ответственного исследования механизмов конструирования и воспроизводства полового неравенства. Гендерный нейтралитет в контексте властных отношений представляет собой одну из самых опасных социальных иллюзий, поскольку согласие с ним делает невидимыми основные причины репрессии гендерного порядка.

Апелляция к биологии и основанному на ней «естественному порядку вещей» помимо сокрытия истинных причин существующего ассиметричного распределения гендерных ролей и социальных привилегий представляет собой один из самых успешных механизмов легитимации существующего общественного 
порядка, в рамках которого господство одних групп людей над другими объявляется нормальным и неизбежным.

Более того, М. Киммел настаивает на существовании еще одного значимого механизма поддержания гендерного неравенства. «Невидимость мужского» представляет собой настолько важный и при этом мастерски завуалированный социальный феномен, что его значимость достаточно сложно считывается в современном обществе. Действительно, никого не удивляет то, что женские и, более широко, гендерные исследования распространены прежде всего среди исследователей женского пола. Слушателями курсов по феминистской и гендерной проблематике также в большинстве своем являются женщины. Создается впечатление, что гендер - вообще исключительно женское измерение, никоим образом не затрагивающее мужчин, которые продолжают восприниматься как мерило объективности «вне гендера». Эта достаточно древняя спекулятивная традиция универсализации мужского, впервые глубоко исследованная в работе Георга Зиммеля «Женская культура» [1], остается актуальной несмотря на развитие и институционализацию гендерных исследований.

«Невидимость мужского»в действительных мужских практиках представляет собой некий «попутный ветер», который поддерживает и направляет людей, обладающих в этом обществе привилегиями быть мужчиной, представителем среднего класса и гетеросексуалом. Те, кому посчастливилось иметь этот попутный ветер, зачастую не замечают его существования, приписывая те или иные социальные, экономические и политические достижения исключительно своим способностям. «Пришло время сделать этот ветер видимым» [7, с. 42], - пишет М. Киммел.

Мужское ускользает от всяких обозначений, скрываясь за литературным, историческим, объективным, научным и т. п. Мужские, по сути, культура, литература, история представляются в общественном дискурсе как универсальные дисциплины, подчеркивая таким образом специфичность, частность и, как следствие, сомнительность женского вклада в общечеловеческое наследие.
Политические основания сокрытия мужского в социальном дискурсе, таким образом, становятся очевидными: универсализация мужского подчеркивает специфичность женского, поддерживая и воспроизводя основные принципы гендерного неравенства.

\section{«Анатомия - это судьба»}

Для последовательного обоснования своего базового тезиса о том, что различия между полами формируются гендерным неравенством, а не лежат в его основе, М. Киммел обращается к анализу теории биологического эссенциализма, согласно которой «все дело в нашей природе!» [2, с. 40].

Главное отличие современного способа обоснования существования половых различий и их фундаментального значения на социальном уровне состоит в апелляции к научному дискурсу, в то время как до XIX столетия ведущая позиция в поддержании и обосновании гендерной иерархии отводилась теологии.

Несмотря на то что основной посыл первой научной теории, включившейся в полемику о природе и предназначении полов, - эволюционной биологии, в корне противоречил христианской концепции творения, она активно поддержала консервативную теологическую риторику относительно естественности подчиненного положения женщин в обществе. Для мыслителей того времени признание половых различий и гендерного неравенства бесспорным научным фактом создало незыблемую платформу для объявления любых попыток изменить существующее положение вещей борьбой против законов природы. Подчиненное положение женщин стало рассматриваться как уникальный природный путь к «женскому счастью», что само по себе исключает стремление к высшему образованию, политические права и свободы, экономическую мобильность.

В XX в. социальный дарвинизм уступил место обоснования полового неравенства другому научному направлению - социобиологии. Данная концепция поддерживает классическую логику «от биологии к культуре». «В вопросе о различиях, - замечает Киммел, - социобиологи обращают особое внимание на сексуальность женщины и мужчины. По их 
мнению, различия в женском и мужском сексуальном поведении явились результатом многих веков эволюционного развития. Эволюционный успех предполагает, что все особи вида - сознательно или бессознательно стремятся передавать свои гены дальше. Таким образом, особи мужского и женского пола развивают репродуктивные “стратегии" для обеспечения передачи своего генетического кода следующим поколениям» [2, с. 45]. Сами стратегии передачи генов обусловливают различные типы мужского и женского сексуального поведения. Эволюционный успех достигается полигамным поведением самца, который стремится осуществить как можно больше оплодотворений, в то время как репродуктивные особенности самки вынуждают ее предпочитать качество количеству, находя наиболее надежный вариант для оплодотворения и дальнейшего удержания экономических ресурсов самца в целях заботы о потомстве. Таким образом, репродуктивные механизмы обусловливают сексуальное поведение, а оно уже, в свою очередь, формирует мужские и женские психологические особенности. Таким способом биология постепенно влияет на социум, для которого распределение мужских и женских социальных ролей становится одним из важнейших системообразующих элементов.

Биологические процессы оправдывают в этой концепции не только «типичную» мужскую неразборчивость в выборе партнерш, тесно связанную с полигамией и безответственным отношением к заботе о подрастающем поколении, но и практики сексуального насилия, в которых мужчина якобы только реализует свое природное предназначение, подчиняясь стратегии передачи своего генетического материала.

Гены, таким образом, рассматриваются как уникальные строители человеческой культуры, формирующие единственно возможную социальную картину, в контексте которой сосуществуют агрессивные неразборчивые самцы и тяготеющие к моногамии самки. М. Киммел обращает внимание на то, что подобная однозначная интерпретация научных фактов не учитывает культурную и социальную историю человечества, в рамках которой моногамия может быть проинтерпретирована не только как способ удержания полигамного от природы самца. В действительности моногамия не в меньшей мере выгодна самцу, поскольку является эффективным способом установления контроля над самкой за неимением других способов убедиться в том, что потомство несет генетический материал данного самца. Более того, эта теория не учитывает и очевидные факты, такие как распространенность однополых контактов у большинства биологических видов, а также то, что сексуальное насилие имеет отношение не столько к «передаче генетического материала», сколько к агрессии и самоутверждению. Именно поэтому насилие сопровождается унижением, а часто и убийством жертвы, что само по себе никак не укладывается в стратегию передачи генов.

Как следует из вышесказанного, научные данные могут порождать различные нарративы, так или иначе трактующие устройство социума. Поэтому, с точки зрения М. Киммела, необходимо сделать вывод о неверности исходного тезиса о природной обусловленности социальных процессов. Причины социального неравенства нужно искать в истории и культуре, а не в биологии. Тем более это верно в отношении гендерного неравенства, которое теснейшим образом связано с определенным типом интерпретации изначально внебинарного биологического материала. Как утверждает М. Киммел, «биология обеспечивает сырье, в то время как общество и история обеспечивают контекст, инструкцию, которой мы следуем, чтобы строить наши идентичности» [2, с. 146].

Исторически сформированное гендерное неравенство постепенно «закостеневает» и обретает видимость некой природной данности, которая, будучи следствием, обретает статус первопричины. «Если человека долго держат в темной комнате, - отмечает Киммел, - и затем внезапно включают свет, то, приспосабливаясь к свету, человек испытывает трудности. Неужели вы сделаете в этом случае заключение, что у этого человека есть генетически обусловленные аномалии зрения по сравнению с теми, кто все время живет при свете?» [2, с. 77-78] Гендерное неравенство - та самая темнота, которую для того, чтобы преодолеть, необходимо как минимум 


\section{ФИЛОСОФИЯ}

осознать как таковую. Худший способ обращения с этой ситуацией - пытаться искать за социальным конструктом незыблемые биологические константы. Основная причина биологического эссенциализма, таким образом, скрывается в классической привычке устанавливать каузальную связь от физиологии к психологии везде, где обнаружена какое-либо отношение между явлениями физического и психического порядка. Какими бы убедительными ни были открытия в области биологии, сделанные современными учеными или учеными в далеком будущем, их значение для человеческого сообщества будет зависеть от того социального и культурного контекста, в котором конкретные люди осуществляют отношения между собой и строят свои уникальные идентичности. «Биологические исследования, - пишет Киммел, - могут предложить нам основные строительные блоки, на которых будут базироваться опыт и идентичность, но только в рамках наших культур, наших обществ и наших семей эти строительные блоки собираются в удивительно разнообразную архитектуру нашей жизни» [2, с. 80].

Таким образом, в концепции М. Киммела обосновывается необходимость обращения к исследованию исторических и культурных истоков того неравноправия полов, которое, скрываясь за разнообразной риторикой «естественности», продолжает быть одним из системообразующих элементов западной цивилизации.

\section{Политика гендера}

Таким образом, на основании приведенных выше доводов гендерная идентичность должна быть признана социокультурным конструктом, представляющим и воспроизводящим в культурном контексте ту или иную интерпретацию фактического материала человеческой физиологии. В подавляющем большинстве примеров эта интерпретация строится в бинарном контексте мужского доминирования, а следовательно, может быть рассмотрена в политическом аспекте. Политика в данном случае означает некий принцип распределения властных отношений в обществе, согласно которому некоторые группы людей удерживают за собой целый ряд социальных, экономических и иных преференций. Однако М. Киммел настаивает на том, что данный принцип не только распределяет преференции между определенными группами людей, обладающих объективными различиями, но и, прежде всего, формирует данные значимые различия. «Невозможно объяснить гендер без соответствующего понимания власти, не потому что власть является следствием гендерного различия, а потому что власть - именно то, что производит гендерные различия. В то время как другие теории объясняют мужское доминирование как результат половых различий, социальный конструкционизм видит в различиях результат доминирования» [2, с. 154].

Более того, политический контекст рассмотрения гендерного неравенства открывает, что не только различия между мужчинами и женщинами формируются, поддерживаются и романтизируются в обществе благодаря данному неравенству. Сложные, напряженные, иерархичные отношения между самими мужчинами на основе расовых, классовых, этнических, сексуальных, возрастных и иных спецификаций также в значительной степени связаны с принципом мужского доминирования и гендерного неравенства. Именно социальный императив мужского превосходства, предполагающий демонстрацию гетеросексуальности, материального благосостояния и других атрибутов успеха формирует болезненное ощущение различия у тех мужчин, которые по самым разным причинам не имеют возможности соответствовать данным требованиям. В то же время репрессивное давление императива мужского превосходства приводит к распространению разнообразных практик гендерного насилия, целью которых является подтверждение и демонстрация гендерных различий, основанных на превосходстве мужчин над женщинами и состоявшихся мужчин над «неудачниками» любой ценой.

Таким образом, политический аспект гендера становится явным по мере того, как акцент в рассмотрении половой дифференциации переносится из сферы индивидуальных особенностей в сферу социальных отношений, основанных на различении, имплицитно содержащем репрессивные механизмы доминирования. «Я показал, - пишет М. Киммел, - что гендерное неравенство не только производит 
наблюдаемые различия, но и рождает культурные стимулы искать различия, для которых нет или почти нет реальных оснований» [2, c. 407].

Другими словами, социализация индивида осуществляется в гендеризованном обществе, где неравенство полов представляет собой один из системообразующих институциональных принципов. Именно поэтому «обретение гендера» или «делание гендера» в процессе социализации не может быть отнесено к развитию индивидуальных задатков человека. Скорее воспитание включает взрослеющего человека в общественную систему посредством последовательной «гендеризации», инкорпорирующей систему доминирования через усвоение языка различий в сознание человека, что, в свою очередь, формирует определенный способ самовосприятия. Осваивая язык половых различий, индивид обретает свое доминирующее или подчиненное «место» в социуме.

Значимую роль в этом процессе включения индивида в систему социального неравенства играют социальные институты, прежде всего такие как семья, школа и рабочее место. В рамках этих фундаментальных образований индивид впервые обретает представление о существовании различий и их крайней важности для успешной социализации. А дальнейшая жизнедеятельность в рамках этих же институций поощряет и подтверждает правильность различения и естественность различий.

\section{Общество без гендера?}

В заключении исследования основных механизмов гендеризованного общества М. Киммел обращается к постановке итогового вопроса своей работы. Если гендерная идентичность не задана природой и не является атрибутом индивидуальности, но, прежде всего, имеет отношение к механизмам власти и господства, гендеризующим общественную систему и создающим различие полов, то осознание этого факта должно неминуемо привести к освобождению от гендера. Если гендер представляет собой мощнейший репрессивный механизм, включающий индивида в сложную систему доминирования и подчинения, то деконструкция гендера становится неминуемой. Но что может представлять собой общество, лишенное гендерных маркеров? Никто из нас никогда не жил в таком обществе, наши тела и наш образ мысли, самопонимания и осмысления мира являются носителями гендерной системы знаков и отличий. Таким образом, исследование гендерного неравенства обращает исследователя к необходимости деконструкции фактически единственного известного способа организации общественной системы.

Каким может быть дегендеризованное человечество? Не превратится ли оно в неиерархичное, но одновременно и неразличимое месиво однотипных субъектов, жизнь которых навсегда лишится тех красок, которые сообщают людям маркеры различения, даже ценой насильственного включения в систему доминирования? «Дело не в том,- пишет М. Киммел, - чтобы женщины и мужчины стали еще больше походить друг на друга, чем сейчас, а в том, что все психологические черты, установки и поведение, которые мы, как носители данной культуры, определяем как "мужественные" и “женственные", нуждаются в пересмотре. Эти черты и установки, в конце концов, несут в себе положительные и отрицательные ценности, и именно из-за иерархии ценностей, из-за их неравнозначности гендерное неравенство тесно переплетается с гендерным различием» [2, с. 408].

Действительно, будучи гендеризованными субъектами, люди с опасением относятся к преодолению гендерных различий. Однако существенный пересмотр представлений о мужественности и женственности уже имеет место в обществе, последовательно смягчая императив противопоставления мужской и женской «природы». Женские практики за последнее столетие претерпели настолько значительные трансформации, что в большинстве стран мира никого не удивляет существование женщин-ученых, женщин-политиков или женщин-менеджеров. Расширяя свои возможности и горизонты, женщины вопреки многовековым обычаям осваивают самые разные профессии, добиваясь в них значительного успеха. С другой стороны, мужчины постепенно начинают приходить к осознанию того, что традиционная идеология долгое время лишала их права развивать в себе эмоциональ- 
ную открытость, эмпатию, нежность, «выбрасывала» их из семьи в целях обретения высокого статуса, материального благополучия, профессионального успеха ценой отстраненного отношения к собственным детям и отчуждения в отношениях с экономически зависимой женой. По мере того, как женщины «выходят» из семьи, стремясь сочетать роли матери и жены с профессиональным ростом, мужчины возвращаются в семью, открывая высокую ценность межличностного общения, партнерских отношений с супругой, трудностей и радостей вовлеченного отцовства.

В традиционном обществе мужчина не мог позволить себе настоящего глубокого отцовства. Отвечая за обеспечение семьи, образование детей, защиту семейных интересов, он оставался отстраненным от ежедневных собственно родительских забот, «ему не нужно было появляться в детской комнате» [5, c. 59]. М. Киммел считает, что революция гендерного сближения, которую можно наблюдать в современном обществе, открывает невозможные ранее положительные перспективы, важнейшей из которых является счастье отцовства. Анализируя собственный опыт, он вспоминает, что когда показания сонограммы впервые определенно указали на пол его будущего сына, один из друзей Майкла иронически заметил: «Теперь-то ты поймешь, что все это биология» [6]. Очевидно, имелось в виду, что, воспитывая мальчика, Киммел осознает, насколько противоположность полов в действительности определяется биологией. Киммел описывает в одной из своих статей, как однажды его сын развеял эти опасения. Гуляя в парке, М. Киммел, его сын и мать играли вместе в игру «противоположности», называя по очереди противоположные друг другу по смыслу слова: короткое - длинное, высокое - низкое, быстрое - медленное и т. д. Обращаясь к сыну Майкла, Захарию, его бабушка спросила: «Захарий, а что будет противоположностью слову “мальчик”?» «Все мое тело напряглось, - вспоминает Майкл. - Я подумал: вот оно, Марс и Венера, гендерная оппозиция, которую я с таким трудом старался избежать в процессе воспитания». Захарий посмотрел на свою бабушку и произнес: «Мужчина» [6].

Таким образом, мужское и женское предстают в теории М. Киммела той бинарной оппозицией, которая не определяется природой, но конструируется социумом в традиционной культуре. Мужественность и женственность - социальные категории, содержание которых должно пересматриваться каждый раз, когда человечество выходит на новый уровень понимания себя.

\section{СПИСОК ЛИТЕРАТУРЫ}

1. Зиммель, Г. Женская культура / Г. Зиммель // Избранное. В 2 т. Т. 2. Созерцание жизни / Г. Зиммель. - М. : Юрист, 1996. - С. 234-265.

2. Киммел, М. Гендерное общество / М. Киммел. - М. : РОССПЭН, 2006. - 464 с.

3. Сиксу, Э. Выходы / Э. Сиксу // Гендерная теория и искусство. Антология: 1970-2000 / под ред. Л. М. Бредихиной, К. Дируэлл. - М. : РОССПЭН, 2005. - С. 47-57.

4. Kimmel, M. A black woman took my job / M. Kimmel // New Internationalist. - 2004. - Iss. 373. Electronic text data. - Mode of access: https:// www.newint.org/features/2004/11/01/men/ (date of access: 15.05 .2017$)$. - Title from screen.

5. Kimmel, M. A war against boys? / M. Kimmel // Tikkun Magazine. - 2002. - Vol. 15, iss. 6. - P. 57-60.

6. Kimmel, M. About a boy / M. Kimmel // Vassar. - 2003. - Vol. 100, iss. 1. - Electronic text data. - Mode of access: http://vq.vassar.edu/issues/ 2004/01/last-page (date of access: 23.03.2017). - Title from screen.

7. Kimmel, M. Toward a pedagogy of the oppressor / M. Kimmel // Tikkun Magazine. - 2002. Vol. 17, iss. 6. - P. 42-45.

\section{REFERENCES}

1. Simmel G. Zhenskaya kultura [Women's Culture]. Izbrannoe. V 2 t. T. 2. Sozertsanie zhizni [Selected Works in 2 vols. Vol. 2. Contemplation of Life]. Moscow, Yurist Publ., 1996, pp. 234-265.

2. Kimmel M. Gendernoe obshchestvo [Gender Society]. Moscow, ROSSPEN Publ, 2006. 464 p.

3. Siksu H. Vykhody [Outputs]. Bredikhina L.M., Diruell K., eds. Gendernaya teoriya i iskusstvo. Antologiya: 1970-2000 [Gender Theory and Art. Anthology: 1970-2000]. Moscow, ROSSPEN Publ., 2005, pp. 47-57.

4. Kimmel M. A Black Woman Took My Job. New Internationalist, 2004, no. 373. URL: https:// newint.org/ features/2004/11/01/men/. (accessed May 15, 2017).

5. Kimmel M. A War Against Boys? Tikkun Magazine, 2002, vol. 15, no. 6, pp. 57-60. 
6. Kimmel M. About a Boy. Vassar, 2003, vol. 100, iss. 1. URL: http://vq.vassar.edu/issues/2004/01/lastpage/. (accessed March 23, 2017).
7. Kimmel M. Toward a Pedagogy of the Oppressor. Tikkun Magazine, 2002, vol. 17, no. 6, pp. $42-45$.

\section{Information About the Author}

Ekaterina B. Khitruk, Candidate of Philosophical Sciences, Associate Professor, Department of Ontology, Theory of Knowledge and Social Philosophy, Tomsk State University, Prosp. Lenina, 36, 634050 Tomsk, Russian Federation, lubomudr@vtomske.ru.

\section{Информация об авторе}

Екатерина Борисовна Хитрук, кандидат философских наук, доцент кафедры онтологии, теории познания и социальной философии, Томский государственный университет, просп. Ленина, 36, 634050 г. Томск, Российская Федерация, lubomudr@vtomske.ru. 